\title{
Fresh and Hardened Properties of Engineered Geopolymer Composite with MgO
}

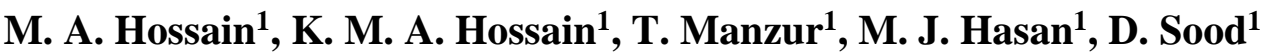 \\ ${ }^{1}$ Ryerson University \\ 350 Victoria St, Toronto, Canada \\ mohammadali.hossain@ryerson.ca; ahossain@ryerson.ca; tmanzur@ryerson.ca; jihan.hasan@ryerson.ca; \\ dhruv.sood@ryerson.ca
}

\begin{abstract}
In this paper, the early results of an ongoing investigation on self-healing engineered geopolymer composites (EGC) are presented. The EGC was developed using powder based alkali activators and $\mathrm{MgO}$ was added as self-healing agent. Two types of source materials were used to produce EGC. One EGC mix had slag and class $\mathrm{C}$ fly ash as source materials and termed as binary mix. The other one had slag, class C fly ash and class F fly ash and termed as ternary mix. Setting time, slump flow, fresh density and rheology were measured as fresh properties of the developed geopolymer composites. As hardened properties, compressive and direct tensile strengths were evaluated. It was observed that addition of $\mathrm{MgO}$ delayed the setting time of both the EGC mixes. The rheology of the developed geopolymer mixes complemented the hardened properties of the mixes. It was found that binary geopolymer mix exhibited superior performance as compared to its ternary counterpart due to presence of class $\mathrm{C}$ fly ash only that ensured higher amount of $\mathrm{CaO}$. It was also observed that EGC, developed in the present study, experienced strength values (both compressive and direct tensile) that are comparable to the values of the previous studies even with the addition of $\mathrm{MgO}$. Moreover, strain hardening characteristic was observed for both EGC mixes under direct tension test. Hence, it is evident that the initial outcomes of the experimental investigation are quite promising and exhibit the importance of conducting further comprehensive studies in order to develop design guidelines for EGC with self-healing capability.
\end{abstract}

Keywords: Engineered geopolymer composites; powder based activators; MgO; Binary mix; Ternary mix; Strain hardening

\section{Introduction}

It is beyond doubt that construction industry is facing enormous challenge to meet the ever increasing demand for Portland cement [1]. Moreover, production of Portland cement requires considerable amount of energy consumption due to clinker calcinations and grinding of raw materials [2-4]. The high energy consumption of cement manufacturing process also results in high emission of $\mathrm{CO}_{2}$. Each ton of Portland cement clinker production emits around 0.9 to 1 ton of $\mathrm{CO}_{2}[5,6]$. Consequently, it has been estimated that $\mathrm{CO}_{2}$ emission from cement production constitutes about $8 \%$ of global $\mathrm{CO}_{2}$ emission [7]. Hence, it is obvious that cement manufacturing process has severe impact on environment. In this context, significant attempts have already been initiated to reduce the environmental impact of cement production through reduction of clinker content. The clinker content is reduced by replacing it with supplementary cementitious materials (SCMs) like ground granulated blast furnace slag (GGBS), natural pozzolans, fly ash (FA) etc. [2, 8, 9]. Such utilization of SCMs definitely enhances the sustainability of cement and concrete industry. However, considering the rapid growth of cement industries due to fast urbanization, particularly in developing parts of the world, development of clinker free concrete is of immense potential for reduction of $\mathrm{CO}_{2}$ emission from construction industry.

Geopolymer (GP) is a clinker free binder and is considered as a promising alternative to Portland cement since it can achieve comparable strength and better durability [1, 10-12]. Application GP can reduce up to $80 \%$ of $\mathrm{CO}_{2}$ emission as compared to Portland cement by totally replacing clinker with FA and/or GGBS [13, 14]. GP is amorphous alkali aluminosilicate in which tetrahedral silicate and aluminate are linked through covalent bonds in a three-dimensional structure. The geopolymerization process involves quick reaction of silica $(\mathrm{Si})$ and alumina $(\mathrm{Al})$ under alkaline condition. Therefore, raw materials of GP must consist of two components i.e., reactive aluminosilicate solids and alkaline activating agent. In fly ash/slag based geopolymer, FA and/or GBBS supply free $\left[\mathrm{SiO}_{4}\right]^{-}$and $\left[\mathrm{AlO}_{4}\right]^{-}$in the solution in the presence of alkaline activating agent i.e., alkali hydroxide/alkali silicate. Common solution based alkaline reagents used to produce geopolymer 
are sodium hydroxide, potassium hydroxide, sodium silicate and potassium silicate $[1,15]$. The $\left[\mathrm{SiO}_{4}\right]^{-}$and $\left[\mathrm{AlO}_{4}\right]^{-}$units form three-dimensional polymeric chain of $\mathrm{Si}-\mathrm{O}-\mathrm{Al}-\mathrm{O}$ bonds by sharing oxygen atom as shown in Equations 1 and 2 [1, 16, 17]. This aluminosilicate gel acts as a binder in geopolymer based cementitious composites.

$$
\begin{aligned}
& \left(\mathrm{Si}_{2} \mathrm{O}_{5} \mathrm{Al}_{2} \mathrm{O}_{2}\right)_{n}+\mathrm{H}_{2} \mathrm{O}+\mathrm{OH}^{-} \rightarrow \mathrm{Si}(\mathrm{OH})_{4}+\mathrm{Al}(\mathrm{OH})^{4-} \\
& \mathrm{Si}(\mathrm{OH})_{4}+\mathrm{Al}(\mathrm{OH})^{4-} \rightarrow\left(\begin{array}{c}
\mathrm{Si}-\mathrm{O}-\underset{\mid}{\mid} \mathrm{Al}-\mathrm{O} \\
\mid
\end{array}\right)_{n}+4 \mathrm{H}_{2} \mathrm{O}
\end{aligned}
$$

Alkali activator solution plays a very important role to initiate the geopolymerization process [18]. In activation process of geopolymerization reactions, the most dominant parameters are the nature and concentration of activators [18, 19]. Komljenovic et al. [19] utilized five different alkali activator solutions and found activation potential of the activators in the order of $\mathrm{Na}_{2} \mathrm{SiO}_{3}>\mathrm{Ca}(\mathrm{OH})_{2}>\mathrm{NaOH}>\mathrm{NaOH}+\mathrm{Na}_{2} \mathrm{CO}_{3}>\mathrm{KOH}$ based on compressive strength of the developed geopolymers. In addition, the properties of solution based geopolymers have been found to be depended on $\mathrm{SiO}_{2} / \mathrm{Al}_{2} \mathrm{O}_{3}$ ratio, curing temperature, molarity of alkali activators solution, amount of water addition, $\mathrm{R}_{2} \mathrm{O} / \mathrm{Al}_{2} \mathrm{O}_{3}$ ratio and $\mathrm{SiO}_{2} / \mathrm{R}_{2} \mathrm{O}$ ratio (where, $\mathrm{R}$ $=\mathrm{Na}^{+}$or $\left.\mathrm{K}^{+}\right)[1,18,20-24]$. It is evident that a significant number of studies are available in literature on development of solution based geopolymer. However, utilization of solution based activators possesses several limitations to be executed in field conditions to produce large volume of geopolymers $[25,26]$. High temperature curing is usually required to activate the polymerization reaction in FA based geopolymer with activator solutions [27, 28]. In addition, application of large volume of solution based activators in the field is quite difficult due to high alkalinity and corrosive nature [25, 29]. Some recent studies show that relative small quantities of alkali activators in powder form (as compared to solution based activators) can activate source materials at ambient temperature [25, 30, 31]. Therefore, difficulties associated with field application and production cost of geopolymer can be lessened by using dry mix of source materials and activators. However, study on dry mix based geopolymers is still quite limited and further research works should be conducted for developing specification and design guidelines specifically for geopolymers with powder based activators.

Researchers at Ryerson University have played significant role in developing ultra-high performance concrete (UHPC), self-consolidating concrete (SSC), lightweight self-consolidating concrete (LWSCC), and engineered cementitious composites (ECC) mixes [32-35]. A comprehensive study has undertaken recently by the same research group to develop geopolymer based smart engineered cementitious composite (smart EGC: smart Engineered Geopolymer Composite) with self-healing and/or self-sensing properties using dry mix technique. Self-healing EGC has been proposed to develop using $\mathrm{MgO}$ type expansive agent since $\mathrm{MgO}$ has already been successfully incorporated to develop self-healing ECC [36]. In this article, the initial results of the experimental investigation on EGC with $\mathrm{MgO}$ are presented. The geopolymers have been produced using two different combinations of FA-Class C (FA-C), slag and FA-Class F (FA-F) using activators in powder form. Commercially available Polyvinyl alcohol (PVA) fiber has been used to produce EGC. Several relevant fresh and hardened properties of geopolymer mortar/EGC with $\mathrm{MgO}$ have been evaluated to demonstrate the effect of addition of $\mathrm{MgO}$ within geopolymer. The authors believe that findings of the study would contribute significantly for conducting further research to develop EGC with self-healing ability.

\section{Materials and Methodology}

The binary and ternary geopolymer mixtures were developed by mixing FA-C+slag and FA-C+slag+FA-F, respectively as reactive aluminosilicate solids with fine silica sand (SS), water and polycarboxylate based high range water reducing admixture (HRWRA/SP). Commercially available Polyvinyl alcohol (PVA) fiber with $8 \mathrm{~mm}$ in length and $40 \mu \mathrm{m}$ in diameter was used to produce engineered geopolymer composite. The PVA fiber surface was coated with $2 \%$ oil by weight to reduce fiber/matrix frictional bond. A particular combination of $\mathrm{Na}_{2} \mathrm{SiO}_{3}$ and $\mathrm{Ca}(\mathrm{OH})_{2}$ was used as alkali activator in powder form

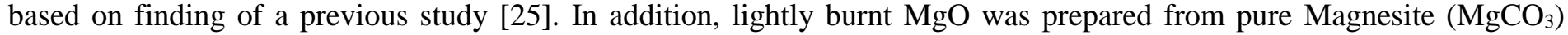
following the procedure described in [37] to be used as self-healing agent with geopolymers. The details of prepared EGC mixes with $\mathrm{MgO}$ are provided in Table 1. Geopolymer mortar was prepared following the same mix proportions except the addition of PVA fibers. 
As fresh properties, setting time and rheology of geoplolymer mortar with $\mathrm{MgO}$ and slump flow and fresh density of EGC with $\mathrm{MgO}$ were evaluated. Setting time was measured following ASTM C807 standard [38]. Brookfield DV3T Rheometer was used to determine the rheology of geopolymer mortar. The slump flow and fresh density of EGC were measured as per ASTM C1611 [39] and ASTM C138 [40] standards, respectively. Compressive and direct tension (Dogbone) tests of EGC were determined following ASTM C109 [41] and ASTM E8 [42] procedures, respectively. The hardened density of EGC was evaluated following conventional procedure. Figure 1 shows samples/setup of different tests conducted in the study.

Table 1: Details of binary and ternary mixes

\begin{tabular}{|c|c|c|c|c|c|c|c|c|}
\hline Mix ID & $\begin{array}{c}\text { Types of Source } \\
\text { Materials (SM) }\end{array}$ & $\begin{array}{c}\text { SM proportion } \\
\text { (Parts by } \\
\text { mass })\end{array}$ & MgO* & Activator* & $\begin{array}{c}\text { Silica } \\
\text { Sand }\end{array}$ & SP* & $\begin{array}{c}\text { PVA** }^{* *} \\
\text { Water/SM } \\
(\mathrm{w} / \mathrm{S})\end{array}$ \\
\hline $\mathrm{BM} 1 \mathrm{~F}+\mathrm{MgO}$ & FA-C+slag & 1 & 0.05 & 0.1 & 0.3 & 0.02 & 0.02 & 0.35 \\
\hline TM1F +MgO & FA-C+slag+FA-F & 1 & 0.05 & 0.1 & 0.3 & 0.02 & 0.02 & 0.35 \\
\hline
\end{tabular}

*weight proportion with respect to $\mathrm{SM}$; **volume proportion with respect to total volume of the mix

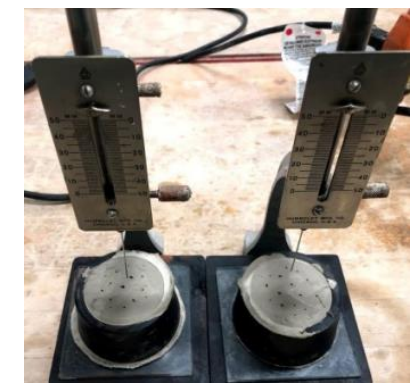

(a) Setting time test

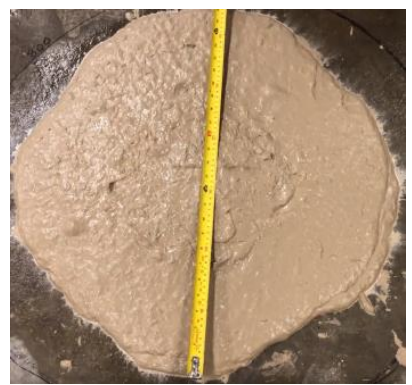

(b) Slump flow test

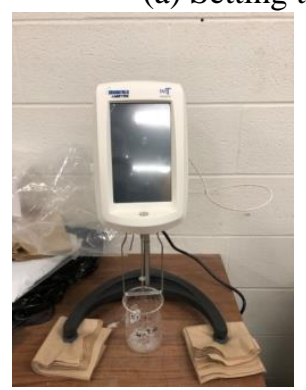

(c) Rheology setup

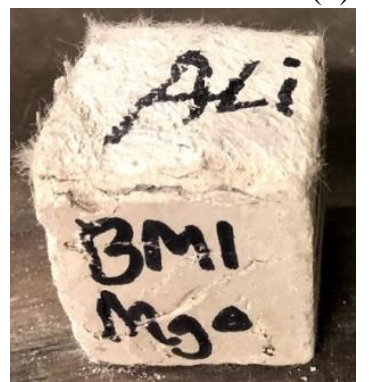

(c) Compressive strength test samples

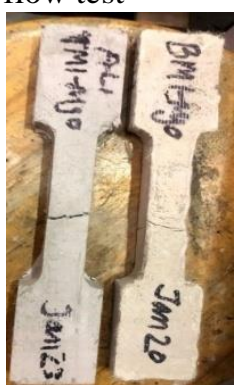

(d) Dogbone test specimens

Fig. 1: Samples prepared for different tests.

\section{Results and Discussion}

\subsection{Setting Time and Densities of the Mixes}

The initial and final setting times of geopolymer mortar are provided in Table 2. For each mix composition, two sets of samples were tested and the deviation in observed values in almost all cases was found to be around $\pm 2 \%$. It is evident that geopolymer with binary mix $(\mathrm{BM} 1 \mathrm{~F}+\mathrm{MgO})$ experienced relatively early setting as compared to its ternary counterpart (TM1F+MgO). The initial and final setting times of BM1F mix were observed to be about 36 and 40 minutes less than that of TM1F mix, respectively. The presence of FA-F in ternary mix was responsible for the delay in setting times of TM1F since it increased the $\mathrm{SiO}_{2} / \mathrm{Al}_{2} \mathrm{O}_{3}$ ratio [1]. In addition, delay in setting time through addition of $\mathrm{MgO}$ was also evident from 
the experimental results since previous studies observed initial setting time of up to 120 minutes for typical geopolymer mixes $[1,43]$. Such behaviour was due to the retarding effect of $\mathrm{MgO}$ within geopolymer matrix. Table 2 also shows fresh and hardened densities of EGC mixes. Both mixes showed almost identical fresh and hardened density values.

Table 2: Summary of setting time, fresh and hardened density

\begin{tabular}{|c|c|c|c|c|}
\hline \multirow{2}{*}{ Sample name } & \multicolumn{2}{|c|}{ Setting time } & Fresh density & $\begin{array}{c}\text { Hardened density } \\
\left(\mathrm{kg} / \mathrm{m}^{3}\right)\end{array}$ \\
\cline { 2 - 3 } & Initial (min) & Final $(\mathrm{min})$ & & \\
\hline $\mathrm{BM} 1 \mathrm{~F}+\mathrm{MgO}$ & 164 & 230 & 2207 & 2017 \\
\hline TM1F+MgO & 200 & 270 & 2209 & 2013 \\
\hline
\end{tabular}

\subsection{Rheology and Slump Flow}

Material rheology characterizes its consistency, how it will spread over a surface as well as deformation characteristics $[44,45]$. When it comes to cement by-products or as such (pastes, mortars or concrete), rheology seems to affect their microstructural, mechanical and durability features, together with their fluidity [45]. During rheological testing, flocs formed due to hydration process are broken down by running a viscometer with a consistent shear rate. As for this study, rheology of the two geopolymer mortar mixes were observed using Brookfield DV3T Rheometer and were subjected to a rotor speed of $20 \mathrm{rpm}$. Figure 2 shows variation of viscosity of two mixes with respect to time. For each mix composition, three sets of samples were tested and the variation in observed values in almost all cases was found to be 3 to $5 \%$. Initially, viscosity of the binary mix decreased from a value of $9100 \mathrm{cP}$ (Centipoise) to $7150 \mathrm{cP}$ in 15 minutes. This can be accounted to still workable mix. As the time progressed, more water was used for hydration. Therefore, the mix started to set and loosed its consistency and thus, the viscosity increased from $7150 \mathrm{cP}$ to around $12500 \mathrm{cP}$. Torque values were also observed to show similar trend of variation within the range of $36 \%$ to $27 \%$ that was within limit (10\% to $100 \%$ ). As for ternary mix, the variation over time was observed to be less fluctuating. However, the value, similar to the binary mix, first reduced to 5850 cP within 15-20 minutes and then increased up to $8191 \mathrm{cP}$ as the mix started to set. The torque values were observed to decrease from $15 \%$ to around $11 \%$ and then rose up to $16 \%$. Both the trend showed that the mixes exhibited high viscosity value as it started to set and loose consistency. However, the binary mix experienced relative high viscosity over time due to presence of high amount of $\mathrm{CaO}$ that eventually resulted in better hydration. The strength test results discussed in Section 2.3 also complement this hypothesis.

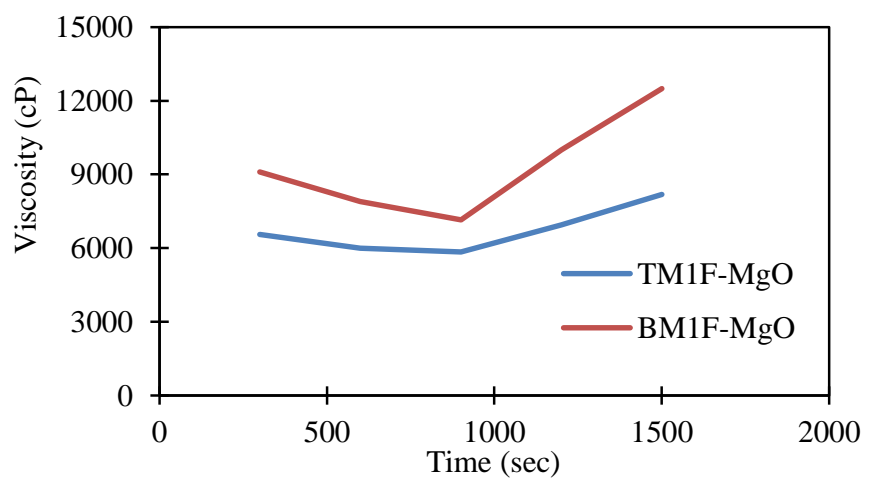

Fig. 2: Variation of viscosity with time.

The slump flow test was conducted using the traditional slump cone. The slump cone was completely filled without any vibration and the time required to reach a spread of $500 \mathrm{~mm}$ (from the moment of lifting up the cone) by the EGC mixes was measured. This is called the $\mathrm{T}_{50}$ measurement and typically varies between 2 and 10 seconds for self-consolidating concrete. 
The $\mathrm{T}_{50}$ measurement for $\mathrm{BM} 1 \mathrm{~F}+\mathrm{MgO}$ was 7 second and for $\mathrm{TM} 1 \mathrm{~F}+\mathrm{MgO}$ was $8 \mathrm{sec}$. Hence, both EGC mixes exhibited very good flow satisfying criteria for self-consolidating concrete.

\subsection{Compressive and Direct Tensile Strengths}

Figure 3(a) shows the compressive strengths of the developed EGC mixes at different ages of 7, 14 and 28 days. For each mix composition and each day, a set of five samples were cast and the standard deviation of the obtained results were in the range of \pm 1 to $2 \mathrm{MPa}$. The highest 28 day compressive strength of $41.5 \mathrm{MPa}$ was achieved by the binary EGC (BM1F$\mathrm{MgO}$ ) mix. The 28 day compressive strength of the ternary mix (TM1F-MgO) was 38.4 MPa. The relative lower strength of ternary mix was due to comparatively lower activation of FA-C [25]. From previous studies it has been found that compressive strength of fly ash based geopolymer with solution based activator ranged from 30 to $80 \mathrm{MPa}[1,46]$ depending on water to geopolymer solid (source materials) ratio and curing temperature. On the other hand, compressive strengths of EGC were found to be in the range of 17.4 to $54.6 \mathrm{MPa}$ in previous research studies conducted by Ohno and Li [47] and Nematollahi et al. [48]. Both studies used fly ash as source materials and combinations of $\mathrm{NaOH}$ and $\mathrm{Na}_{2} \mathrm{SiO}_{3}$ as activators. The maximum compressive strength of the geopolymer mix [46] and EGC [48] was achieved by the water to source materials $(\mathrm{w} / \mathrm{S})$ ratio of 0.18 and 0.20 , respectively. Both the w/S ratios were significantly less than the ratio used in the current study. Hence, there is scope for further improvement in compressive strength of $\mathrm{EGC}$ with $\mathrm{MgO}$ by reducing the water content. Moreover, addition of $\mathrm{MgO}$ increased the water demand and caused dilution of source material that resulted in further decrease in strength attainment. However, $\mathrm{MgO}$ contributes to attainment of strength at later age through formation of M-S$\mathrm{H}$ which was outside the scope of the present article. Considering all the above mentioned factors, it could be concluded that EGC with $\mathrm{MgO}$ exhibited satisfactory performance in compressive strength tests.

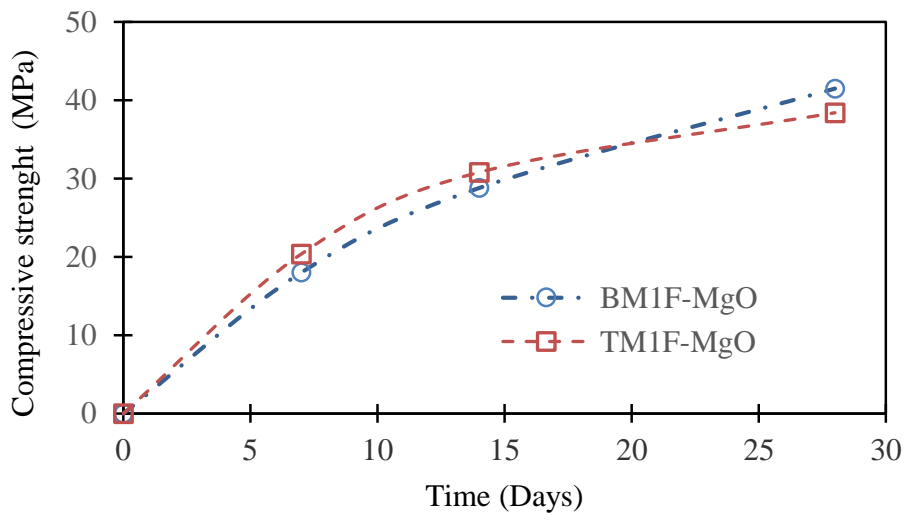

(a)

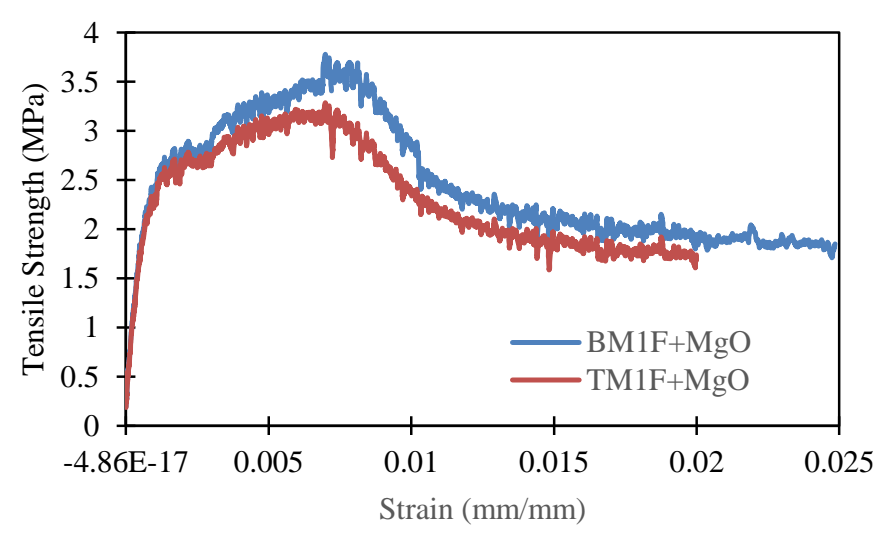

(b)

Fig. 3: (a) Compressive strength of EGC mixes; (b) Stress vc strain relationship of EGC mixes obtained from direct tension tests.

Figure 3(b) shows the tensile strength vs strain graphs of both the EGC mixes with $\mathrm{MgO}$ at 28 days obtained from direct tension test. Similar to compressive strength, the binary mix exhibited superior performance in the direct tension test. The maximum tensile strength of 3.8 and 3.3 MPa was achieved by the binary and ternary mix, respectively. Previous studies on EGC by Ohno and Li [47] and Nematollahi et al. [48] found uni-axial tensile strength ranged from 2.9 to $3.4 \mathrm{MPa}$ and 3.9 to 5.2 MPa, respectively. Therefore, tensile strengths obtained in the current study by EGC with dry mix activators and MgO are comparable to previous studies and further enhancement can be expected resulting from the late pozzolanic reactions between $\mathrm{Mg}(\mathrm{OH})_{2}$ and $\mathrm{Si}$. In addition, both EGC mixes with $\mathrm{MgO}$ experienced strain hardening, the prerequisite to develop engineered geopolymer composites. 


\section{Conclusions}

The study presents early results of an ongoing comprehensive investigation on engineered geopolymer composites (EGC) with powder based/dry mix activators and MgO. Magnesium Oxide was added to develop self-healing EGC. Two EGC mixes were produced using combination of FA-C+slag and FA-C+slag+FA-F termed as binary and ternary mix, respectively. The following conclusions can be drawn from the present study;

- The binary mix exhibited relatively quicker initial and final setting times as compared to ternary mix. In addition, both EGC mixes experienced comparatively slower setting times in comparison with conventional geopolymer mixes due to addition of $\mathrm{MgO}$.

- The binary mix experienced higher viscosity with time than that of ternary mix resulting from better hydration caused by higher amount of $\mathrm{CaO}$. Torque values of both the EGC mixes were found to be within the limit.

- The binary mix achieved higher compressive strength at 28 days in comparison with ternary mix. However, both the EGC mixes experienced compressive strengths that are comparable to the strength of geopolymer mixes of previous studies having similar water to source material ratio. Moreover, the long term pozzolanic reaction of $\mathrm{MgO}$ addition has not been considered in this study which could further improve the strength of the EGC mixes.

- Similar to compressive strength, the binary mix achieved higher tensile strength than that of ternary mix. The tensile strengths of both the EGC mixes are comparable to the previous studies despite addition of $\mathrm{MgO}$ which has retarding effect on strength attainment.

- Both EGC mixes exhibited satisfactory strain hardening characteristics.

It is, therefore, obvious that initial outcomes of the experimental investigation are quite promising and exhibit potential of developing EGC as sustainable construction materials. However, further studies with more sample size will be required to develop design specifications for EGC.

\section{Acknowledgements}

The authors acknowledge the financial support from Natural Sciences and Engineering Research Council (NSERC) Canada.

\section{References}

[1] B. Singh, G. Ishwarya, M. Gupta and S. K. Bhattacharyya, "Geopolymer concrete: A review of some recent developments," Journal of Construction and Building Materials, vol. 85, pp. 78-90, 2015.

[2] Z. Zhang, J. L. Provis, A. Reid and H. Wang, "Geopolymer foam concrete: An emerging material for sustainable Construction," Journal of Construction and Building Materials, vol. 56, pp. 113-127, 2014.

[3] M. Schneider, M. Romer, M. Tschudin and H. Bolio, "Sustainable cement production - present and future," Cement and Concrete Research, vol. 41, no. 7, pp. 642-50, 2011.

[4] J. S. Damtoft, J. H. Lukasik, D. Sorrentino and E. M. Gartner, "Sustainable development and climate change initiatives," Cement and Concrete Research, vol. 38, no. 2, pp. 115-127, 2008.

[5] P. K. Mehta, Sustainable cements and concrete for the climate change era - a review.," in Proceedings of the second international conference on sustainable construction materials and technologies, Università Politecnica delle Marche, Ancona, Italy, 2010, pp. 1-10.

[6] J. Zhang, P. Zhang, Y. Zheng and K. Wang, "A review on properties of fresh and hardened geopolymer mortar," Composites Part B, vol. 152, pp. 79-95, 2018.

[7] J. G. K. Olivier, G. Janssens-Maenhout G, J. A. H. W. Peters, "Trends in global $\mathrm{CO}_{2}$ emissions; 2012 report," PBL Netherlands Environmental Assessment Agency, The Hague, Netherlands, 2012.

[8] R. Bleszynski, R. D. Hooton, M. D. A. Thomas and C. A. Rogers, "Durability of ternary blend concrete with silica fume and blast-furnace slag, laboratory and outdoor exposure site studies," ACI Materials Journal, vol. 99, no. 5, pp. 499$508,2002$. 
[9] C. A. Hendriks, E. Worrell, D. de Jager, K. Blok and P. Riemer, "Emission reduction of greenhouse gases from the cement industry," in Proceedings of the $4^{\text {th }}$ International Conference on Greenhouse Gas Control Technologies, Interlaken, Austria, August 30-September 2, IEA GHG R\&D Programme, UK, 1998.

[10] P. Duxon, A. Fernandez-Jiminez, J. L. Provis, G. C. Luckey, A. Palomo, J. S. J. Van Deventure, "Geopolymer technology: the current state of the art," Journal of Material Science, vol. 42, no. 29, pp. 17-33, 2007.

[11] J. L. Provis, J. S. J. VanDeventer, editors, Geopolymers, structure, processing, properties and application. Woodhead Publishing Limited, 2009.

[12] C. $\mathrm{Li}, \mathrm{H}$. Sun and L. Li, "A review: the comparison between alkali-activated slag $(\mathrm{Si}+\mathrm{Ca})$ and metakaolin $(\mathrm{Si}+\mathrm{Al})$ cements," Cement and Concrete Research, vol. 40, no. 13, pp. 41-9, 2010.

[13] A. Hassan, M. Arif and M. Shariq, "Use of geopolymer concrete for a cleaner and sustainable environment - A review of mechanical properties and microstructure," Journal of Cleaner Production, vol. 223, pp. 704-728, 2019.

[14] Y. Ding, J-G. Dai and C-J.Shi, "Mechanical properties of alkali-activated concrete: A state-of-the-art review," Construction and Building Materials, vol. 127, pp. 68-79, 2016.

[15] F. Shaikh and A. Fairchild, "Strain hardening behaviour of polyethylene fibre reinforced ambient air cured geopolymer composite," RILEM Book series, vol. 15, pp. 162-171, 2018.

[16] C-K. Maa, A. Z. Awang and W. Omar, "Structural and material performance of geopolymer concrete: A review," Journal of Construction and Building Materials, vol. 186, pp. 90-102, 2018.

[17] K. A. Komnitsas, "Potential of geopolymer technology towards green buildings and sustainable cities," Procedia Engineering, vol. 21,pp. 1023-1032, 2011.

[18] P. W. Ken, M. Ramli and C. C. Ban, "An overview on the influence of various factors on the properties of geopolymer concrete derived from industrial by-products," Journal of Construction and Building Materials, vol. 77, pp. 370-395, 2015.

[19] M. Komljenovic, Z. Bascarevic and V. Bradic, "Mechanical and microstructural properties of alkali-activated fly ash geopolymers," Journal of Hazardous Materials, vol. 181, no. 1-3, pp. 35-42, 2010.

[20] J. G. S. van Jaarsveld and J. S. J. van Deventure, "Effect of alkali metal activators on the properties of fly ash-based geopolymer," Industrial \& Engineering Chemistry Research, vol. 38, no. 10, pp. 3932-3941, 1999.

[21] H. Xu and J. S. J. van Deventure, "Geopolymerisation of multiple minerals," Minerals Engineering, vol. 15, no. 12, pp. 1131-1139, 2002.

[22] B. Zhang, K. J. D. MacKenzie and I. W. M. Brown, "Crystalline phase formation in metakaolinite geopolymers activated with $\mathrm{NaOH}$ and sodium silicate," Journal of Materials Science, vol. 44, no. 17, pp. 4668-4676, 2009.

[23] P. D. Silva, K. S. Crenstil and V. Sirivivatnanon, "Kinetics of geopolymerization: role of $\mathrm{Al}_{2} \mathrm{O}_{3}$ and $\mathrm{SiO}_{2}$," Cement and Concrete Research, vol. 37, pp. 512-518, 2007.

[24] A. S. de Vargas, D. C. C. DalMolin, A. C. V. Vilela, F. J. da Silva, B. Pavão and H. Veit, "The effects of $\mathrm{Na}_{2} \mathrm{O} / \mathrm{SiO}_{2}$ molar ratio, curing temperature and age on compressive strength, morphology and microstructure of alkali-activated fly ash-based geopolymers," Cement and Concrete Composites, vol. 33, pp. 653-60, 2011.

[25] D. Sood, K. M. A. Hossain, T. Manzur and M. J. Hasan, Developing geopolymer pastes using dry mixing technique, in Proceedings of the CSCE Annual Conference: Growing with youth - Croitre avec les jeunes, Laval (Greater Montreal), Canada, June 12-15, 2010.

[26] B. Nematollahi, J. Sanjayan, and F. U. A. Shaikh, "Synthesis of heat and ambient cured one-part geopolymer mixes with different grades of sodium silicate," Ceramics International, vol. 41, pp. 5696-5704, 2015.

[27] O. A. Abdulkareem, A .M. M. A. Bakri, H. Kamarudin, I. K. Nizar and A. E. A. Saif, "Effects of elevated temperatures on the thermal behavior and mechanical performance of fly ash geopolymer paste, mortar and lightweight concrete," Journal of Construction and Building Materials, vol. 50, pp. 377-387, 2014.

[28] D. L. Kong and J. G. Sanjayan, "Effect of elevated temperatures on geopolymer paste, mortar and concrete," Cement and Concrete Research, vol. 40, no. 2, pp. 334-339, 2010.

[29] B. Nematollahi, J. Sanjayan and F. U. A. Shaikh, "Tensile Strain Hardening Behavior of PVA Fiber-Reinforced Engineered Geopolymer Composite," Journal of Materials in Civil Engineering, vol. 27, no. 10, 2015. 
[30] Y. Alrefaei, and J-G. Dai, "Tensile behavior and microstructure of hybrid fiber ambient cured one-part engineered geopolymer composites," Journal of Construction and Building Materials, vol. 184, pp. 419-431, 2018.

[31] B. Nematollahi, J. Sanjayan, J. Qiu and E-H. Yang, "Micromechanics-based investigation of a sustainable ambient temperature cured one-part strain hardening geopolymer composite," Journal of Construction and Building Materials, vol. 131, pp. 552-563, 2017.

[32] M. A. A. Sherir, K. M. A. Hossain, M. Lachemi, "Structural performance of polymer fiber reinforced engineered cementitious composites subjected to static and fatigue flexural loading," Polymers, vol. 7, pp. 1299-1330, 2015.

[33] K. M. A. Hossain, C. Mak and D. Ametrano, "GFRP reinforced UHPC composites for sustainable bridge construction," Canadian Journal of Civil Engineering, vol. 29, no. 1, pp. 12-15, 2012.

[34] A. Lotfy, K. M. A. Hossain and M. Lachemi, "Lightweight self-consolidating concrete with expanded shale aggregates: modelling and optimization," International Journal of Concrete Structures and Materials, vol. 9, no. 2, pp. 185-206, 2015.

[35] K. M. A. Hossain, S. Hasib and T. Manzur, "Shear behavior of novel hybrid composite beams made of self-consolidating concrete and engineered cementitious composites," Engineering Structures, vol. 202, 109856, 2020.

[36] M. A. A. Sherir, K. M. A. Hossain and M. Lachemi, "The influence of MgO-type expansive agent incorporated in selfhealing system of Engineered cementitious Composites," Journal of Construction and Building Materials, vol. 149, pp. 164-185, 2017.

[37] M. A. A. Sherir, K. M. A. Hossain and M. Lachemi, "Self-healing and expansion characteristics of cementitious composites with high volume fly ash and MgO-type expansive agent," Journal of Construction and Building Materials, vol. 127, pp. 80-92, 2016.

[38] ASTM C807, "Standard test method for time of setting of hydraulic cement mortar by modified vicat needle," ASTM International, West Conshohocken, PA, 2018.

[39] ASTM C1611 / C1611M, "Standard test method for slump flow of self-consolidating concrete," ASTM International, West Conshohocken, PA, 2018.

[40] ASTM C138 / C138M, "Standard test method for density (unit weight), yield, and air content (gravimetric) of concrete," ASTM International, West Conshohocken, PA, 2017.

[41] ASTM C109 / C109M, "Standard test method for compressive strength of hydraulic cement mortars (using 2-in. or [50mm] cube specimens)," ASTM International, West Conshohocken, PA, 2016.

[42] ASTM E8 / E8M, "Standard test methods for tension testing of metallic materials," ASTM International, West Conshohocken, PA, 2016.

[43] A. Antoni1, S. W. Wijaya and D. Hardjito, "Factors affecting the setting time of fly ash-based geopolymer," Materials Science Forum, vol. 841, pp. 90-97, 2016.

[44] L. Halasta, P. Rovnanik and O. Mikhailova, "Effect of geopolymer composition on the mechanical and rheological properties," Materials Science and Engineering, vol. 583, 2019.

[45] F. Puertas, M. M. Alonso, S. Gismera, M. Lanzón and M. T. Blanco-Varela, "Rheology of cementitious materials: alkali-activated materials or geopolymers," MATEC Web of Conferences, vol. 149, 2018.

[46] D. Hardjito, S. E. Wallah, D. M. J. Sumajouw and B. V. Rangan, "On the development of fly ash-based geopolymer concrete," ACI Materials Journal, vol. 101, pp. 467-72, 2004.

[47] M. Ohno and V. C. Li, "A feasibility study of strain hardening fiber reinforced fly ash-based geopolymer composites," Journal of Construction and Building Materials, vol. 57, pp. 163-168, 2014.

[48] B. Nematollahi, J. Sanjayan and F. U. A. Shaikh, "Matrix design of strain hardening fiber reinforced engineered geopolymer composite," Composites Part B: Engineering, vol. 89, pp. 253-265, 2016. 